\title{
Trends, clinical outcomes, and cost implications of mitral valve repair versus replacement, concomitant with aortic valve replacement
}

\author{
Arman Kilic, MD, Joshua C. Grimm, MD, J. Trent Magruder, MD, Christopher M. Sciortino, MD, PhD, \\ Glenn J. R. Whitman, MD, William A. Baumgartner, MD, and John V. Conte, MD
}

\begin{abstract}
Objective: This study evaluated national trends, clinical outcomes, and cost implications of mitral valve (MV) repair, versus replacement, concomitant with aortic valve replacement (AVR).
\end{abstract}

\begin{abstract}
Methods: Patients who underwent MV surgery concomitant with AVR, between 1999 and 2008, were identified in the Nationwide Inpatient Sample (NIS) registry. Mitral stenosis, endocarditis, and emergency cases were excluded. Inpatient clinical outcomes and costs were compared. Costs were derived using cost-to-charge ratios supplied by the dataset for each individual hospital. Multivariable logistic and linear regression analyses were used for risk adjustment.
\end{abstract}

\begin{abstract}
Results: A total of 41,417 concomitant cases were identified, of which 11,472 (28\%) were MV repairs. Repair rates increased from $15.3 \%$ in 1999 to $43.5 \%$ in $2008(P<.001)$. Major postoperative morbidity rates were similar with MV repair, versus replacement, concomitant with AVR (each $29 \%, P=.54$ ). Unadjusted inpatient mortality $(7.9 \%$ vs $10.1 \%, P=.005)$; length of hospital stay (median: 8 vs 9 days, $P<.001$ ); and costs (median: $\$ 45,455$ vs $\$ 49,648, P<.001$ ) were lower with MV repair. After risk adjustment, MV repair was associated with lower odds of inpatient mortality, and with lower costs (each $P<.001$ ).

Conclusions: Mitral valve repair concomitant with AVR is associated with reduced inpatient mortality and costs, compared with MV replacement, supporting its use when technically feasible. Although use has increased substantially, MV repair continues to comprise a minority of concomitant AVR cases, in centers reporting to the NIS registry. Increasing repair rates, particularly in NIS-participating hospitals, seems prudent. (J Thorac Cardiovasc Surg 2015;149:1614-9)
\end{abstract}

See related commentary on pages $1620-1$.

In isolated mitral valve (MV) surgery, MV repair has been employed with increasing frequency. An analysis ${ }^{1}$ of the Society of Thoracic Surgeons (STS) database found that MV repair rates in participating hospitals rose from $51 \%$ in 2000 to $69 \%$ in 2007 . The main advantages of MV repair, compared with replacement, include avoidance of anticoagulation and prosthesis-related complications. In addition, multiple studies have demonstrated that isolated MV repair is a durable operation associated with reduced perioperative mortality and improved long-term survival, compared with replacement. ${ }^{2-4}$

In the setting of MV surgery concomitant with aortic valve replacement (AVR), compared with isolated cases,

\footnotetext{
From the Division of Cardiac Surgery, Department of Surgery, The Johns Hopkins Medical Institutions, Baltimore, Md.

Received for publication Sept 29, 2014; revisions received Feb 7, 2015; accepted for publication Feb 19, 2015.

Address for reprints: John V. Conte, MD, Division of Cardiac Surgery, The Johns Hopkins Hospital, 1800 Orleans St, Suite 7107, Baltimore, MD 21287 (E-mail: jconte@jhmi.edu).

$0022-5223 / \$ 36.00$

Copyright (c) 2015 by The American Association for Thoracic Surgery

http://dx.doi.org/10.1016/j.jtcvs.2015.02.044
}

considerably less evidence is available regarding choice of MV repair versus replacement. Mitral valve surgery concomitant with AVR is less common than isolated MV surgery or AVR, constituting $<15 \%$ of these cases. ${ }^{5-7} \mathrm{~A}$ recent report using data from the STS registry found that MV repair was associated with lower adjusted odds of operative mortality, compared with MV replacement, in the setting of concomitant AVR. ${ }^{8}$ Whether this early survival advantage is demonstrable in other multiinstitutional datasets is unclear. In addition, isolated MV repair has been associated with lower inpatient costs, compared with replacement, although the cost benefit in cases concomitant with AVR remain to be elucidated. ${ }^{9}$ In this study, we evaluated "real-world" trends, clinical outcomes, and cost implications of MV repair, versus replacement, concomitant with AVR.

\section{METHODS \\ Data Source}

The data source for this study was the Nationwide Inpatient Sample (NIS). The NIS registry contains deidentified patient-level data and is provided as part of the Agency for Healthcare Research and Quality Healthcare Cost and Utilization Project. The database is robust and provides a snapshot of the "real world," containing a $20 \%$ stratified sample of all hospitals in the United States. Data on 8 million inpatient hospitalizations from $>1050$ participating hospitals are included. ${ }^{10}$ In addition to patient-level data, operative variables, hospital characteristics, and inpatient cost data are provided. 


\section{Abbreviations and Acronyms \\ AVR = aortic valve replacement \\ $\mathrm{CABG}=$ coronary artery bypass grafting \\ MV $=$ mitral valve \\ NIS = Nationwide Inpatient Sample \\ STS $=$ Society of Thoracic Surgeons}

\section{Study Population}

The study population included patients undergoing MV repair or replacement, concomitant with AVR, between January 1, 1999 and December 31, 2008, who are included in the NIS database. Codes from the International Classification of Diseases (9th edition) were used to identify the study cohort. The procedural codes 35.21 and 35.22 were used to identify AVRs. Code 35.12 was used for MV repair, and codes 35.23 and 35.24 were used for MV replacement. To create a homogenous study population that was more likely to be amenable to MV repair, we excluded patients who had mitral stenosis and infected endocarditis, as well as emergency cases.

\section{Baseline Characteristics and Trend Analysis}

Baseline characteristics were compared for the cohorts who underwent MV repair, versus replacement, concomitant with AVR. These included: patient demographics; comorbidities; primary insurance type; presence of aortic stenosis; mechanical aortic valve versus aortic bioprosthesis; rheumatic disease; concomitant procedures, including coronary artery bypass grafting (CABG) and tricuspid valve repair and replacement; and hospital characteristics, including teaching status, size, rural versus urban location, and region. In addition, year of operation and surgeon and hospital MV-surgery volume were evaluated. A trend analysis was performed that demonstrated the number of concomitant AVR and MV cases that were comprised of MV repairs per year.

\section{Clinical Outcomes}

The primary clinical outcome was inpatient mortality. All causes of death were factored into assessing this outcome. Major postoperative morbidity rates for MV repair versus MV replacement were compared. Complications that were evaluated included: pneumonia, hemorrhage, acute renal failure, stroke, sepsis, gastrointestinal bleeding, wound complication, cardiac shock, and pulmonary embolus. Other clinical outcomes included the need for a postoperative ventricular assist device as postcardiotomy support, a postoperative intra-aortic balloon pump, and permanent pacemaker or automatic internal cardioverter-defibrillator implantation. In addition, length of hospital stay for the 2 groups was compared.

\section{Cost Outcomes}

Another principal outcome was inpatient costs of care associated with MV repair, versus replacement, concomitant with AVR. The NIS registry provides total charges for the inpatient stay. Costs are then derived using cost-to-charge ratios that are developed for each individual hospital by the Agency for Healthcare Quality and Research, using Centers for Medicare and Medicaid data. These ratios are used to account for the inherent variability among hospitals and regions in how much is charged for a given procedure. Inpatient costs, rather than charges, were used as the primary economic outcome because costs better reflect actual resource use, whereas charges reflect pricing decisions related to payer policies and other factors that are unrelated to resource use.

\section{Risk-Adjusted Analyses}

Multivariable logistic regression analysis was conducted to evaluate the risk-adjusted impact of MV repair on inpatient mortality. All of the baseline variables discussed previously, including the use of concomitant procedures, were evaluated for potential inclusion in the multivariable model. Entry criteria for the multivariable model included an association with inpatient mortality in univariate logistic regression analysis (exploratory $P$ value $<.20$ ) and $<20 \%$ missing data.

In addition, a multivariable linear regression model was created to evaluate the risk-adjusted impact of MV repair on inpatient costs. Again, all of the baseline patient, operative, and hospital-related variables listed previously were evaluated for potential inclusion. Entry criteria for this model were the same as for the mortality model: univariate association $(P<.20)$ and $<20 \%$ missing data. Continuous data are presented as mean $\pm \mathrm{SD}$; frequency data are presented as number (percentage), unless otherwise noted. Statistical analyses were performed with STATA software, version 11 (Stata Corporation, College Station, Tex).

\section{RESULTS}

\section{Baseline Characteristics}

An estimated total of 41,417 eligible patients undergoing concomitant MV surgery and AVR were identified. This number included 29,945 (72\%) MV replacements and $11,472(28 \%)$ MV repairs. A comparison of baseline characteristics between the cohorts showed several significant differences. The group of patients who underwent MV repair was older, had a higher percentage of men, and had a higher percentage of Medicare insurance (Table 1). This group had a lower percentage of patients who had atrial fibrillation or chronic obstructive pulmonary disease, but a higher percentage who had prior myocardial infarction, peripheral vascular disease, and diabetes mellitus.

Most patients who underwent replacement had a mechanical MV valve implanted. For the AVR, a lower percentage of the cohort who underwent MV repair, versus MV replacement, had mechanical aortic valves placed (Table 1). Concomitant CABG was more common in the group undergoing MV repair, as was tricuspid valve repair, although rates of tricuspid valve replacement were lower. Mitral valve repairs concomitant with AVR were more commonly performed at teaching hospitals than were MV replacements.

\section{Clinical Outcomes}

The overall unadjusted inpatient mortality rate after MV surgery concomitant with AVR was $9.5 \%$. The unadjusted inpatient mortality rate was significantly lower in the MV repair group ( $8 \%$ vs $10 \% ; P=.005)$ (Table 2). Overall major morbidity rates were similar between the cohorts, although rates of sepsis and acute renal failure were higher, and rate of hemorrhage was lower, with MV repair (Table 2). The need for a postoperative ventricular assist device, intra-aortic balloon pump, permanent pacemaker, or automatic internal cardioverter-defibrillator were each comparable between groups. The mean and median lengths of hospital stay were significantly shorter with MV repair (Table 2).

In multivariable analysis, MV repair, as opposed to replacement, concomitant with AVR was associated with a $37 \%$ riskadjusted decrease in the likelihood of inpatient mortality $(P<.001)$ (Table 3). Other patient-related variables that 
TABLE 1. Patient characteristics for groups undergoing mitral valve replacement versus repair, concomitant with aortic valve replacement

\begin{tabular}{|c|c|c|c|}
\hline Variable & $\begin{array}{l}\text { Mitral valve } \\
\text { replacement } \\
(n=29,945)\end{array}$ & $\begin{array}{l}\text { Mitral valve } \\
\quad \text { repair } \\
(n=11,472)\end{array}$ & $\begin{array}{c}P \\
\text { value }\end{array}$ \\
\hline Age $(y ;$ mean $\pm S D)$ & $65.6 \pm 13.5$ & $68.3 \pm 13.0$ & $<.001$ \\
\hline Gender, female & $17,069(57)$ & $4348(38)$ & $<.001$ \\
\hline Payment status & & & $<.001$ \\
\hline Self-pay or private & $9699(32)$ & $3503(31)$ & \\
\hline Medicare & $17,817(60)$ & $7419(65)$ & \\
\hline Medicaid & $1696(6)$ & $338(3)$ & \\
\hline Other & $691(2)$ & $207(2)$ & \\
\hline \multicolumn{4}{|l|}{ Comorbidities } \\
\hline Atrial fibrillation & $18,099(60)$ & $6031(53)$ & $<.001$ \\
\hline Myocardial infarction & $1500(5)$ & $797(7)$ & .002 \\
\hline Congestive heart failure & $8580(29)$ & $3488(30)$ & .22 \\
\hline Peripheral vascular disease & $1583(5)$ & $948(8)$ & $<.001$ \\
\hline Cerebrovascular disease & $1962(7)$ & $816(7)$ & .35 \\
\hline COPD & 8665 (29) & $2817(25)$ & $<.001$ \\
\hline Diabetes mellitus & 3734 (12) & $1655(14)$ & .04 \\
\hline Chronic renal insufficiency & $1821(6)$ & $829(7)$ & .08 \\
\hline Liver disease & $173(0.6)$ & $25(0.2)$ & .06 \\
\hline Mechanical aortic valve & $18,448(63)$ & $5119(47)$ & $<.001$ \\
\hline $\begin{array}{l}\text { Mechanical mitral valve } \\
\text { if mitral valve replacement }\end{array}$ & $18,448(63)$ & N/A & N/A \\
\hline \multicolumn{4}{|l|}{ Concomitant procedures } \\
\hline CABG & $9482(32)$ & $4602(40)$ & $<.001$ \\
\hline Tricuspid repair & $1417(5)$ & $799(7)$ & .001 \\
\hline Tricuspid replacement & $452(2)$ & $43(0.4)$ & $<.001$ \\
\hline Teaching hospital & $20,903(30)$ & $7357(36)$ & .02 \\
\hline Urban location of hospital & $29,375(98)$ & $11,199(98)$ & .29 \\
\hline Large hospital & $22,570(75)$ & $8616(75)$ & .56 \\
\hline Hospital region & & & .51 \\
\hline Northeast & 7052 (24) & $2483(22)$ & \\
\hline Midwest & $6436(21)$ & 2795 (24) & \\
\hline South & 9673 (32) & 3728 (32) & \\
\hline West & $6784(23)$ & $2467(22)$ & \\
\hline
\end{tabular}

Values are $\mathrm{n}(\%)$, unless otherwise indicated. "Large hospital" was defined by the dataset, based on hospital's urban status, teaching status, and region. $C O P D$, Chronic obstructive pulmonary disease; $N / A$, not applicable; $C A B G$, coronary artery bypass grafting; $S D$, standard deviation.

were significant predictors of inpatient mortality were: older age, female gender, and comorbidities, specifically prior myocardial infarction, congestive heart failure, peripheral vascular disease, cerebrovascular disease, chronic renal insufficiency, and liver disease. Atrial fibrillation was protective. Patients undergoing concomitant $\mathrm{CABG}$ were at increased risk of mortality, as were patients with Medicare or "other" insurance type. Regional differences showed that, after concomitant MV surgery and AVR, those in the South region had higher riskadjusted odds of mortality. An earlier year of operation, and lower surgeon and hospital MV-surgery volumes, were additionally associated with a significantly higher mortality risk (Table 3). The c-index of the multivariable model was 0.76 .

In patients with preoperative chronic renal insufficiency, the unadjusted mortality rate was $28.4 \%$, versus $8.2 \%$ in
TABLE 2. Unadjusted outcomes of mitral valve repair, versus replacement, concomitant with aortic valve replacement

\begin{tabular}{|c|c|c|c|}
\hline Variable & $\begin{array}{l}\text { Mitral valve } \\
\text { replacement } \\
(n=29,945)\end{array}$ & $\begin{array}{c}\text { Mitral valve } \\
\text { repair } \\
(\mathrm{n}=\mathbf{1 1 , 4 7 2 )}\end{array}$ & $\begin{array}{c}P \\
\text { value }\end{array}$ \\
\hline Inpatient mortality & $3012(10)$ & $904(8)$ & .005 \\
\hline Major morbidity & $8770(29)$ & 3277 (29) & .54 \\
\hline Pneumonia & $1433(5)$ & $559(5)$ & .88 \\
\hline Hemorrhage & $3335(11)$ & $1046(9)$ & .009 \\
\hline Acute renal failure & 3988 (13) & $1779(16)$ & .02 \\
\hline Stroke & $939(3)$ & $327(3)$ & .51 \\
\hline Sepsis & $377(1)$ & $231(2)$ & .03 \\
\hline Gastrointestinal bleeding & $254(0.9)$ & $64(0.6)$ & .14 \\
\hline Wound complication & $785(3)$ & $272(2)$ & .57 \\
\hline Cardiac shock & $142(0.5)$ & $90(0.8)$ & .12 \\
\hline Pulmonary embolus & $34(0.1)$ & $27(0.2)$ & .23 \\
\hline $\begin{array}{l}\text { Postoperative intra-aortic } \\
\text { balloon pump }\end{array}$ & $2174(7)$ & $782(7)$ & .54 \\
\hline $\begin{array}{l}\text { Postoperative ventricular } \\
\text { assist device }\end{array}$ & $55(0.2)$ & $36(0.3)$ & .29 \\
\hline $\begin{array}{l}\text { Permanent pacemaker or } \\
\text { automatic internal } \\
\text { cardioverter-defibrillator }\end{array}$ & $348(1)$ & $153(1)$ & .51 \\
\hline \multicolumn{4}{|l|}{ Length of hospital stay (d) } \\
\hline Mean \pm SD & $13.2 \pm 13.6$ & $12.0 \pm 12.5$ & .002 \\
\hline Median & $9(7-15)$ & $8(6-13)$ & $<.001$ \\
\hline \multicolumn{4}{|l|}{ Cost $(\$)$} \\
\hline Mean \pm SD & $62,296 \pm 44,577$ & $56,547 \pm 39,239$ & $<.001$ \\
\hline Median (IQR) & $\begin{array}{l}49,648 \\
\quad(38,149-70,193)\end{array}$ & $\begin{array}{l}45,455 \\
\quad(34,595-62,777)\end{array}$ & $<.001$ \\
\hline
\end{tabular}

Values (for categoric data) are presented as $\mathrm{n}(\%)$, unless otherwise indicated. Continuous data are presented as mean $\pm \mathrm{SD}$. For median (IQR) values, comparisons were made with the Wilcoxon rank-sum test. $I Q R$, Interquartile range; $S D$, standard deviation.

those without renal insufficiency $(P<.001)$. Mitral valve repair, as opposed to replacement, concomitant with AVR was associated with lower mortality rates in those with chronic renal insufficiency $(19.8 \%$ vs $32.3 \%, P=.01)$. Liver disease was associated with higher mortality rates, ranging from $35.8 \%$ in those with severe liver disease, defined as having associated complications such as ascites, portal hypertension, or varices, to $23.3 \%$ in those with liver disease but without such complications, to $9.4 \%$ in those without liver disease $(P<.001)$.

\section{Cost Outcomes}

The average inpatient cost of MV surgery concomitant with AVR was $\$ 60,577 \pm \$ 43,179$. The unadjusted mean and median costs of care were significantly lower in the MV repair cohort (Table 2). In risk-adjusted multivariable linear regression analysis, MV repair was associated with lower costs, compared with MV replacement (Table 4). The strongest predictors of increased costs included chronic renal insufficiency, concomitant tricuspid valve replacement, and cerebrovascular disease. Other significant predictors of increased costs included older age, congestive 
TABLE 3. Multivariable logistic regression model for inpatient mortality

\begin{tabular}{|c|c|c|}
\hline Covariates & Odds ratio $(95 \% \mathrm{CI})$ & $P$ value \\
\hline Mitral valve repair & $0.63(0.51-0.77)$ & $<.001$ \\
\hline Age (increasing, per y) & $1.04(1.03-1.05)$ & $<.001$ \\
\hline Female gender & $1.53(1.28-1.82)$ & $<.001$ \\
\hline \multicolumn{3}{|l|}{ Payment status } \\
\hline Self-pay or private insurance & Ref. & Ref. \\
\hline Medicare & $1.26(0.98-1.62)$ & .07 \\
\hline Medicaid & $0.68(0.37-1.26)$ & .22 \\
\hline Other & $1.73(0.95-3.15)$ & .07 \\
\hline Atrial fibrillation & $0.50(0.42-0.60)$ & $<.001$ \\
\hline Myocardial infarction & $1.51(1.11-2.05)$ & .008 \\
\hline Congestive heart failure & $1.40(1.18-1.67)$ & $<.001$ \\
\hline Peripheral vascular disease & $1.66(1.25-2.21)$ & $<.001$ \\
\hline Cerebrovascular disease & $1.70(1.30-2.22)$ & $<.001$ \\
\hline Chronic renal insufficiency & $2.01(1.78-2.27)$ & $<.001$ \\
\hline Liver disease & $4.45(1.90-10.4)$ & .001 \\
\hline Aortic valve stenosis & $1.00(0.84-1.20)$ & .97 \\
\hline Concomitant CABG & $1.64(1.38-1.95)$ & $<.001$ \\
\hline Tricuspid valve repair & $1.74(1.24-2.43)$ & .001 \\
\hline Nonteaching hospital & $0.93(0.77-1.12)$ & .42 \\
\hline \multicolumn{3}{|l|}{ Hospital region } \\
\hline Northeast & Ref. & Ref. \\
\hline Midwest & $1.07(0.82-1.40)$ & .63 \\
\hline South & $1.50(1.17-1.91)$ & .001 \\
\hline West & $0.96(0.73-1.27)$ & .79 \\
\hline $\begin{array}{l}\text { Surgeon volume (decreasing, } \\
\text { per } 10 \text { annual cases) }\end{array}$ & $1.09(1.02-1.17)$ & .01 \\
\hline $\begin{array}{l}\text { Hospital volume (decreasing, } \\
\text { per } 10 \text { annual cases) }\end{array}$ & $1.03(1.02-1.05)$ & $<.001$ \\
\hline Year of operation (earlier, per y) & $1.06(1.03-1.09)$ & $<.001$ \\
\hline
\end{tabular}

heart failure, concomitant $\mathrm{CABG}$, tricuspid valve repair, having the operation performed at a teaching hospital, a later year of operation, and lower surgeon and hospital MV-surgery volumes (Table 4). The risk-adjusted impact of MV repair on reduced costs and inpatient mortality persisted when cases involving tricuspid valve repair or replacement and/or CABG were excluded (each $P<.05$ ). Similar results were obtained when total charges were used as the primary outcome, as opposed to costs; MV repair had a significant impact on reduced risk-adjusted charges $(P<.001)$.

\section{DISCUSSION}

\section{Study Findings}

This study evaluated trends, clinical outcomes, and cost implications of MV repair, versus replacement, concomitant with AVR in the United States. In this analysis of $>41,000$ estimated patients, we demonstrated that MV repair concomitant with AVR, compared with MV replacement concomitant with AVR, was associated with: (1) lower unadjusted and risk-adjusted in-hospital mortality; (2) shorter length of hospital stay; and (3) lower unadjusted and risk-adjusted costs of care. In addition, the use of MV
TABLE 4. Multivariable linear regression model for inpatient costs

\begin{tabular}{|c|c|c|}
\hline Covariates & Coefficient $(95 \%$ CI $)$ & $P$ value \\
\hline Mitral valve repair & $-8214(-10,673$ to -5756$)$ & $<.001$ \\
\hline Age (increasing, per y) & 267 (150 to 384$)$ & $<.001$ \\
\hline \multicolumn{3}{|l|}{ Payment status } \\
\hline Self-pay or private insurance & Ref. & Ref. \\
\hline Medicare & $1553(-1489$ to 4596$)$ & .32 \\
\hline Medicaid & $66(-5543$ to 5676$)$ & .98 \\
\hline Other & $-854(-8475$ to 6766$)$ & .90 \\
\hline Atrial fibrillation & $911(-1390$ to 3213$)$ & .44 \\
\hline Congestive heart failure & 6611 (4198 to 9023$)$ & $<.001$ \\
\hline Peripheral vascular disease & $1733(-2678$ to 6144$)$ & .44 \\
\hline Cerebrovascular disease & $11,597$ (7138 to 16,055$)$ & $<.001$ \\
\hline Chronic renal insufficiency & $16,271(14,145$ to 18,397$)$ & $<.001$ \\
\hline Liver disease & $13,436$ ( -2858 to 29,731$)$ & .11 \\
\hline Mechanical aortic valve & 290 ( -2111 to 2691$)$ & .81 \\
\hline Concomitant CABG & 7786 (5386 to 10,186$)$ & $<.001$ \\
\hline Tricuspid valve repair & $8776(4072$ to 13,481$)$ & $<.001$ \\
\hline Tricuspid valve replacement & $16,727$ (6690 to 26,764$)$ & .001 \\
\hline Nonteaching hospital & $-6565(-9030$ to -4100$)$ & $<.001$ \\
\hline \multicolumn{3}{|l|}{ Hospital region } \\
\hline Northeast & Ref. & Ref. \\
\hline Midwest & $-5380(-8.833$ to -1928$)$ & .002 \\
\hline South & $-5592(-8804$ to -2380$)$ & .001 \\
\hline West & $4510(984$ to 8035$)$ & .01 \\
\hline $\begin{array}{l}\text { Surgeon volume (decreasing, } \\
\text { per } 10 \text { annual cases) }\end{array}$ & $655(71$ to 1239$)$ & .03 \\
\hline $\begin{array}{l}\text { Hospital volume (decreasing, } \\
\text { per } 10 \text { annual cases) }\end{array}$ & $275(79$ to 471$)$ & .006 \\
\hline Year of operation (earlier, per y) & $-603(-1114$ to -91$)$ & .02 \\
\hline
\end{tabular}

repair in concomitant cases increased substantially over time, from $15 \%$ in 1999 to $44 \%$ in 2008 .

\section{Study Implications}

The results from our analysis support the use of MV repair, rather than replacement, in concomitant AVR cases for which MV repair is technically feasible. This benefit applies to not only early clinical outcomes but also cost outcomes. With an increasing emphasis on cost containment in healthcare in the United States, the cost implications of various procedures and operations are certainly important to consider. A prior analysis ${ }^{9}$ of isolated MV surgery similarly demonstrated lower average inpatient costs with MV repair versus replacement $(\$ 30,720$ vs $\$ 45,485)$. As expected, the total values for these inpatient costs in isolated MV cases were roughly $\$ 20,000$ less than the costs demonstrated in our analysis in which concomitant AVR was performed.

Another implication of our results relates to use of MV repair in these concomitant cases on a national level. Although the rate of MV repair concomitant with AVR nearly tripled during the 10-year study period (Figure 1), the overall rate is still lower than that reported by the STS database. Moreover, in an analysis of 23,000 patients in 


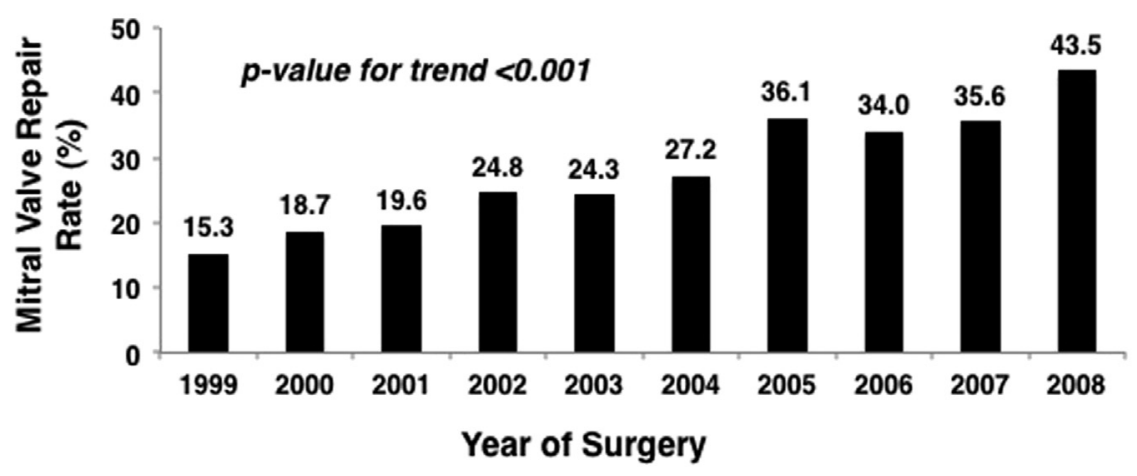

FIGURE 1. Annual rates of mitral valve repair concomitant with aortic valve replacement during the 10-year study period.

the STS registry, rates of MV repair in concomitant AVR cases increased to $59 \%$ in 2007 , compared with $44 \%$ in 2008 in our analysis. ${ }^{8}$ Our data suggest remaining room for improvement in MV repair rates, and that efforts to increase these rates should be particularly emphasized in NIS-participating hospitals. This approach could potentially be accomplished through the development and adoption of repair-enabling technology and through education. In addition, referral to centers and/or surgeons with more experience in MV repair may be prudent, as they have been found to have increased rates of repair, as well as improved outcomes. ${ }^{11,12}$

The unadjusted in-hospital mortality rates reported in our study for MV repair and replacement $(8 \%$ and $10 \%$, respectively) were similar to the rates reported in the analysis of concomitant MV surgery and AVR in the STS database $\left(8 \%\right.$ and $12 \%$, respectively). ${ }^{8}$ Some differences in the study populations between the NIS and STS registries were noted, however; those in the STS database who underwent concomitant MV surgery and AVR were older and more frequently had concomitant CABG. Despite these differences, the independent effect of MV repair in reducing inpatient mortality in adjusted analysis was of similar magnitude in the studies.

\section{Predictors of In-Hospital Mortality}

As expected, being older, being a woman, and having additional concomitant procedures were associated with a higher mortality risk. These risk factors have been identified previously in valve surgery. ${ }^{8}$ In addition, several preoperative comorbidities were found to be correlated with increased mortality risk in our multivariable analysis.

Liver disease, present in only a small minority of patients, was associated with the strongest adverse impact on mortality. The association between liver disease and increased mortality risk in valve surgery is well established, with increasing severity of liver disease correlating with progressively worse survival rates. ${ }^{13,14}$ Even in our study population, which was limited to elective cases, the overall unadjusted in-hospital mortality in patients with liver disease undergoing concomitant AVR and MV surgery was $26.4 \%$, nearly triple the $9.4 \%$ mortality rate in those without liver disease. The mortality rate was even higher, at $35.8 \%$, in patients with complications of liver disease, such as varices, ascites, or portal hypertension.

These data may be useful in discussing prognosis after MV surgery concomitant with AVR for patients who have liver disease. Furthermore, our data suggest that studies should better delineate how liver disease should influence patient selection. Additionally, in the elective setting, preoperative stabilization and optimization of liver function may be prudent in this patient subset, particularly for complications of liver disease, as these have a profound adverse impact on mortality.

Preoperative renal insufficiency was found to be another predictor of increased mortality risk in our study. In patients on dialysis, the clinical benefit of MV repair in isolated cases remains to be firmly established. One analysis of 86,000 patients undergoing isolated MV surgery found that dialysis patients underwent MV repair less frequently, and that MV repair versus replacement patients had comparable short-term outcomes. ${ }^{15}$ Dialysis patients had a nearly 4-fold risk-adjusted increase in mortality risk in their study, with an overall unadjusted mortality rate of $9.3 \%$.

In our analysis, in which all forms of preoperative chronic renal insufficiency were captured, including nondialysis and dialysis patients, this comorbidity carried a $>2$-fold increased risk of operative mortality after adjusting for confounders, with a substantial unadjusted mortality rate of $28.4 \%$. Similar to cases involving liver disease, optimization of renal function, when possible, seems prudent in elective MV surgery concomitant with AVR, owing to its significant impact on operative mortality risk. In contrast to the aforementioned study in isolated MV surgery, in our analysis, MV repair in the setting of concomitant AVR was associated with a significant $12.5 \%$ absolute increase in short-term survival in patients with renal insufficiency. ${ }^{15}$ This finding merits further attention. 


\section{Predictors of In-Hospital Costs}

Of all the comorbidities evaluated, preoperative renal insufficiency had the greatest impact on increased inpatient costs, again underscoring the importance of optimizing renal function before elective MV surgery concomitant with AVR. Mitral valve repair was associated with a substantial reduction in inpatient costs, with a magnitude comparable to that of the opposite effect, created by concomitant tricuspid valve repair, or CABG, of increasing costs. Our analysis therefore supports MV repair, versus replacement, in concomitant AVR cases, when it is technically feasible, from the standpoint of not only improving clinical outcomes, but also reducing costs.

\section{Limitations}

A limitation of this analysis is that all variables that potentially affect clinical outcomes and costs were not available in the NIS registry. These variables include: specific type of MV repair; degree of mitral regurgitation; technical expertise of the operating surgeon; and institutional resources, staffing, and experience in managing higher-risk cardiac surgical patients. Although the NIS registry uses cost-tocharge ratios for individual hospitals, as a means to account for variability among hospitals in amounts charged for similar procedures, accurately assessing inpatient costs is a complex process, susceptible to accounting and reporting errors. Further breakdown of costs, including fixed versus variable costs, and intraoperative versus postoperative costs, is important for comparison purposes, but this level of granularity is not available from the database.

Another limitation is that MV practice is continually evolving, with ongoing trends that may not have been entirely captured by our analysis, such as the increasing use of bioprostheses and the refinement of repair techniques. Additional limitations are that the NIS registry contains claims-based data and may lack detailed clinical data; and it provides estimated totals based on a stratified sample, which contain inherent variability. A proportion of patients who initially had MV repair may have subsequently undergone MV replacement; such patients may have been captured in the data analysis as having undergone only MV replacement. Finally, this study examined in-hospital outcomes, but longer-term data, particularly in evaluation of MV repair versus replacement, are important to consider, as reoperation rates, complications associated with anticoagulation, and long-term survival and quality of life may differ between these 2 approaches.

\section{CONCLUSIONS}

In this study of $>41,000 \mathrm{MV}$ surgeries concomitant with AVR, MV repair was found to be associated with lower risk-adjusted mortality and costs, as well as shorter length of hospitalization, compared with MV replacement. These results collectively support the utilization of MV repair in concomitant AVR cases, when technically feasible. Furthermore, the rate of MV repair, as opposed to replacement, concomitant with AVR seems to be lower in centers that report to the NIS than in reports from STS-participating hospitals. Focusing educational efforts on providers and programs that have lower repair rates is a potential strategy to increase overall national utilization of MV repair in the setting of concomitant AVR.

\section{Conflict of Interest Statement}

Authors have nothing to disclose with regard to commercial support.

\section{References}

1. Gammie JS, Sheng S, Griffith BP, Peterson ED, Rankin JS, O'Brien SM, et al. Trends in mitral valve surgery in the United States: results from the Society of Thoracic Surgeons Adult Cardiac Surgery Database. Ann Thorac Surg. 2009;87:1431-7.

2. Badhwar V, Peterson ED, Jacobs JP, He X, Brennan JM, O’Brien SM, et al. Longitudinal outcome of isolated mitral valve repair in older patients: results from 14,604 procedures performed from 1991 to 2007. Ann Thorac Surg. 2012;94:1870-7.

3. Vassileva CM, Mishkel G, McNeely C, Boley T, Markwell S, Scaife S, et al. Long-term survival of patients undergoing mitral valve repair and replacement: a longitudinal analysis of Medicare fee-for-service beneficiaries. Circulation. 2013; 127:1870-6.

4. Mohty D, Orszulak TA, Schaff HV, Avierinos JF, Tajik JA, Enriquez-Sarano M Very long-term survival and durability of mitral valve repair for mitral valve prolapse. Circulation. 2001;104:I1-7.

5. Jamieson WR, Edwards FH, Schwartz M, Bero JW, Clark RE, Grover FL. Risk stratification for cardiac valve replacement. National Cardiac Surgery Database. Database Committee of The Society of Thoracic Surgeons. Ann Thorac Surg. 1999;67:943-51

6. Hannan EL, Racz MJ, Jones RH, Gold JP, Ryan TJ, Hafner JP, et al. Predictors of mortality for patients undergoing cardiac valve replacements in New York State. Ann Thorac Surg. 2000;70:1212-8.

7. Hellgren L, Kvidal P, Stahle E. Improved early results after heart valve surgery over the last decade. Eur J Cardiothorac Surg. 2002;22:904-11.

8. Thourani VH, Suri RM, Rankin JS, He X, O'Brien SM, Badhwar V, et al. Does mitral valve repair offer an advantage over replacement in patients undergoing aortic valve replacement? Ann Thorac Surg. 2014;98:598-603; discussion 604.

9. Vassileva CM, Shabosky J, Boley T, Markwell S, Hazelrigg S. Cost analysis of isolated mitral valve surgery in the United States. Ann Thorac Surg. 2012;94: 1429-36.

10. Agency for Healthcare Research and Quality Healthcare Cost and Utilization Project. Overview of the Nationwide Inpatient Sample. Available at: http:// www.hcup-us.ahrq.gov/nisoverview.jsp. Accessed June 23, 2014.

11. Bolling SF, Li S, O’Brien SM, Brennan JM, Prager RL, Gammie JS. Predictors of mitral valve repair: clinical and surgeon factors. Ann Thorac Surg. 2010;90: 1904-11.

12. Kilic A, Shah AS, Conte JV, Baumgartner WA, Yuh DD. Operative outcomes in mitral valve surgery: combined effect of surgeon and hospital volume in a population-based analysis. J Thorac Cardiovasc Surg. 2013;146:638-46.

13. Ailawadi G, Lapar DJ, Swenson BR, Siefert SA, Lau C, Kern JA, et al. Model for end-stage liver disease predicts mortality for tricuspid valve surgery. Ann Thorac Surg. 2009;87:1460-7.

14. Morimoto N, Okada K, Okita Y. The model for end-stage liver disease (MELD predicts early and late outcomes of cardiovascular operations in patients with liver cirrhosis. Ann Thorac Surg. 2013;96:1672-8.

15. Vassileva CM, Brennan JM, Gammie JS, Sheng S, Boley T, Saha-Chaudhuri P, et al. Mitral procedure selection in patients on dialysis: Does mitral repair influence outcomes? J Thorac Cardiovasc Surg. 2014;148:144-50.

Key Words: aortic valve replacement, mitral valve repair, mitral valve replacement, health care costs, patient outcomes. 